\title{
BIOEQUIVALENCE OF TWO FEXOFENADINE FORMULATIONS IN HEALTHY HUMAN VOLUNTEERS AFTER SINGLE ORAL ADMINISTRATION
}

\author{
Luis Mendoza ${ }^{a *}$, Pavel Begany ${ }^{\mathrm{a}}$, Marketa Dyrhonova ${ }^{\mathrm{b}}$, Nizam Emritte $^{\mathrm{c}}$, Xenia Svobodova $^{\mathrm{a}}$
}

\author{
a I.Q.A., a.s., Prague, Czech Republic \\ ${ }^{b}$ Bioequivalence Unit, Hospital and Polyclinic in Mělník, Mělník, Czech Republic \\ c Drogsan Pharmaceuticals, Ankara, Turkey \\ e-mail:mendoza@iqa.cz
}

Received: April 24, 2006; Accepted: January 26, 2007

Key words: Fexofenadine/HLPC/AUC/Bioequivalence/Pharmacokinetics

Aim: A randomized, two-way, crossover, bioequivalence study was conducted in 25 fasting, healthy, male volunteers to compare two brands of fexofenadine $180 \mathrm{mg}$ tablets, FEXOFENADINE $180 \mathrm{mg}$ Film Tablet (Drogsan A.S., Ankara, Turkey) as test and Telfast ${ }^{\circledR} 180 \mathrm{mg}$ Tablet (Aventis Pharma, Frankfurt am Main, Germany) as a reference product.

Method: One tablet of either formulation was administered after $10 \mathrm{~h}$ of overnight fasting. After dosing, serial blood samples were collected during a period of 48 hours. Plasma samples were analysed for fexofenadine by a validated HPLC method. The pharmacokinetic parameters $\mathrm{AUC}_{0-48}, \mathrm{AUC}_{0-\alpha}, \mathrm{C}_{\max }, \mathrm{T}_{\max }, \mathrm{K}_{\mathrm{el}}, \mathrm{T}_{1 / 2}$, and $\mathrm{CL}$ were determined from plasma concentration-time profiles for both formulations and were compared statistically.

Results and Conclusions: The analysis of variance (ANOVA) did not show any significant difference between the two formulations and $90 \%$ confidence intervals (CI) fell within the acceptable range, satisfying the bioequivalence criteria of the FDA. Based on these statistical inferences it was concluded that the two brands exhibited comparable pharmacokinetics profiles and that Drogsan's Fexofenadine is equivalent to Telfast ${ }^{\circledR}$ of Aventis Pharma, Frankfurt am Main, Germany.

\section{INTRODUCTION}

Fexofenadine is a selective and peripherally acting $\mathrm{H}_{1}$-receptor antagonist. In clinical studies this nonsedating antihistamine has been found to relieve symptoms associated with allergic conditions such as seasonal allergic rhinitis ${ }^{1,2}$. Results of clinical safety and efficacy trials with fexofenadine $\mathrm{HCl}$ doses up to $240 \mathrm{mg}$ twice daily in patients with seasonal rhinitis have further demonstrated its safety, indicating a large therapeutic window for this $\mathrm{drug}^{3}$. The drug effect is seen within $1 \mathrm{hr}$, achieving maximum effect at $6 \mathrm{hr}$, and lasting a minimum of $12 \mathrm{hr}$ after medication $^{4,5}$, and the drug can be used for long periods without evidence of intolerance ${ }^{6}$.

The objective of this study was to evaluate, in healthy volunteers, the bioequivalence (BE) of a test formulation of the $180 \mathrm{mg}$ (tablets) of fexofenadine $\mathrm{HCl}$ manufactured by Drogsan A.S., Ankara, Turkey (FEXOFENADINE $180 \mathrm{mg}$ Film Tablet) and a commercial formulation of $180 \mathrm{mg}$ (tablets) of fexofenadine $\mathrm{HCl}$ (Telfast ${ }^{\circledR}$ produced by Aventis Pharma, Frankfurt am Main, Germany) used as a reference formulation.

\section{METHODS}

\section{Study design and healthy volunteers}

Twenty-five healthy adult male volunteers aged between 18 and 50 years $(26.3 \pm 6.2$ years, mean \pm S.D. $)$ and within $15 \%$ of the ideal body weight, weight between 67.0 and $111.0 \mathrm{~kg}(80.8 \pm 10.1)$, and height between 170 and $198 \mathrm{~cm}(184.0 \pm 7.4)$, were selected for the study.

All subjects gave written informed consent and the Local Ethics Committee (Hospital and Polyclinic in Mělník) approved the clinical protocol. All volunteers were assessed as healthy based on medical history, clinical examination, blood pressure, ECG and laboratory investigation (hematology, blood biochemistry and urine).

The study was conducted in a randomized, single-dose, two-way, cross-over design with a two-week wash-out period between two doses. During each period, the volunteers were admitted to hospital and after overnight fasting they received a single reference or test $180 \mathrm{mg}$ fexofenadine tablet. Low-carbonate water $(240 \mathrm{~mL})$ was given immediately after drug administration. All volunteers fasted $4 \mathrm{~h}$ after the drug administration, and then they received a snack. Standardized meals (lunch, afternoon snack, dinner and breakfast) were provided to volunteers $6,9,12$ and $24 \mathrm{hr}$ after dosing.

The study was performed in accordance with the guidelines of the revised Declaration of Helsinki on biomedical research involving subjects and the requirements of Good Clinical Practice.

\section{Formulations and sample collection}

The following formulations were employed: FEXOFENADINE $180 \mathrm{mg}$ Film Tablets (lot number 4100001, expiration date 10/2006) as test formulation, 


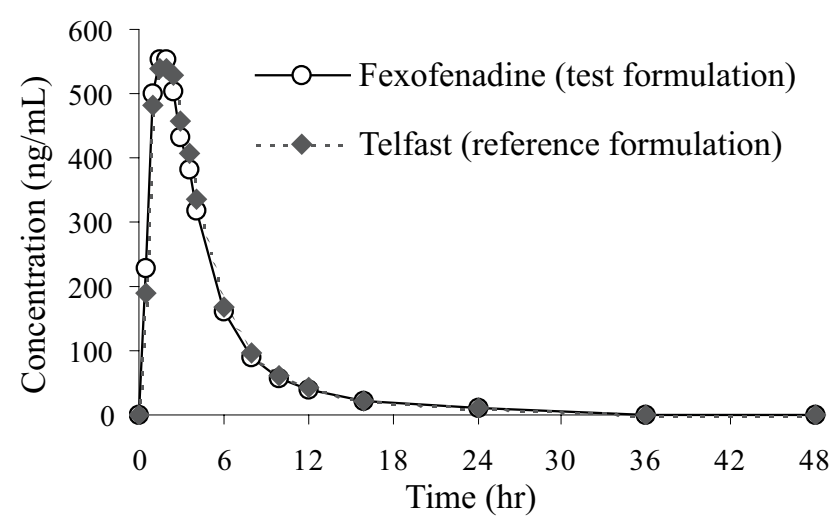

Fig. 1. Fexofenadine plasma mean concentrations versus time profile obtained aftersingle oral administration of $180 \mathrm{mg}$ of fexofenadine tablet formulation.

and Telfast ${ }^{\circledR} 180 \mathrm{mg}$ Tablets (lot number 40D264, expiration date $03 / 2007$ ) as reference formulation.

Blood $(9 \mathrm{ml})$ was sampled from antecubital or cubital veins and collected into sodium citrate-containing tubes before and $0.5,1,1.5,2,2.5,3,3.5,4,6,8,10,12,16$, 24,36 and 48 hours after the administration of each fexofenadine tablet formulation $(180 \mathrm{mg})$. The blood samples were centrifuged at $2500 \mathrm{~g}$ for $10 \mathrm{~min}$ at $4{ }^{\circ} \mathrm{C}$ and the separated plasma was collected and stored at $-20{ }^{\circ} \mathrm{C}$ until drug analysis. After a wash-out period of 14 days, the study was repeated in the same manner to complete the cross-over design.

\section{Drug analysis}

All plasma samples were analysed for fexofenadine concentration according to a sensitive, selective, and accurate high-performance liquid chromatography (HLPC) method, which was developed and validated before the study at the laboratories of I.Q.A..

The chromatographic separations and quantitative determination were performed using a high-performance liquid chromatograph from Agilent Technologies (HPST, Prague, Czech Republic): Model 1100 series, equipped with a degassing unit, quaternary pump, autoinjector, UV detector, and controlled by Agilent Chem. Station software. Chromatographic separation was performed using an Eclipse XDB-C ${ }_{18}(150 \times 4.6 \mathrm{~mm}$ id.; $5 \mu \mathrm{m}$ particle size) HPLC column from Agilent Technologies (HPST, Prague, Czech Republic). The mobile phase consisted of acetonitrile and potassium dihydrogen phosphate $(0.05 \mathrm{~mol} / \mathrm{l}, \mathrm{pH} 5.0)$. The mobile phase was eluted at a flow rate of $1.5 \mathrm{ml} / \mathrm{min}$ at $50{ }^{\circ} \mathrm{C}$. UV detection of fexofenadine and the internal standard (cetirizine) was performed at $195 \mathrm{~nm}$. Each analysis required a maximum of $12 \mathrm{~min}$. The calibration curves were linear over a range of $10-1000 \mathrm{ng} / \mathrm{ml}$ using $1.0 \mathrm{ml}$ plasma samples. All samples from each volunteer were measured on the same day in order to avoid inter-assay variation.

\section{Pharmacokinetic and statistical analysis}

Pharmacokinetic analysis was performed by means of a model-independent method using the GraphPad Prism (rev. 2.01), Lotus Approach and Lotus 1-2-3 (rev. 9) computer programs. The maximum fexofenadine plasma concentration $\left(\mathrm{C}_{\max }\right)$ and the corresponding time of peak plasma concentration $\left(\mathrm{T}_{\max }\right)$ were taken directly from the individual plasma data. The elimination rate constant $\left(\mathrm{K}_{\mathrm{el}}\right)$ was estimated from the slope of the semilogarithmic plot of the terminal phase of the plasma concentrationtime curve calculated by linear regression, and the elimination half-life $\left(T_{1 / 2}\right)$ was generated by dividing $\ln 2$ by the elimination rate constant $\mathrm{K}_{\text {el. }}$ The area under the plasma concentration-time curve $\mathrm{AUC}_{0-48}$ and the area to the infinity $\mathrm{AUC}_{0-\alpha}$ were calculated using the linear trapezoidal method. Extrapolation of these areas to infinity $\left(\mathrm{AUC}_{0-\alpha}\right)$ was done by adding the value $\mathrm{C}_{\text {last }} / \mathrm{k}_{\mathrm{el}}$ to the calculated $\mathrm{AUC}_{0-48}$ (where $\mathrm{C}_{\text {last }}=$ the last detectable concentration). The clearance $(\mathrm{CL})$ was calculated using the following equation (dose/body wt)/ $\mathrm{AUC}_{0-\alpha}$.

For the purpose of bioequivalence analysis, a two-way analysis of variance (ANOVA, GLM procedure) was used to assess the effect of formulations, periods, sequences, and subjects on $\mathrm{AUC}_{0-48}, \mathrm{AUC}_{0-\alpha}$ and $\mathrm{C}_{\max }$ The difference of two related parameters was considered statistically significant for $\mathrm{p}<0.05$.

\section{RESULTS AND DISCUSSION}

Both fexofenadine formulations (FEXOFENADINE and Telfast $180 \mathrm{mg}$ tablets) were well tolerated in all subjects; unexpected serious adverse events that could

Table 1. Arithmetic and geometric means and $90 \%$ confidence intervals $(90 \% \mathrm{CI})$ of $\mathrm{Cmax}, \mathrm{AUC}_{0-48}$ and $\mathrm{AUC}_{0-\alpha}$ (log transformed) of fexofenadine during single dose administration of $180 \mathrm{mg}$ test and reference formulations in 25 healthy male subjects.

\begin{tabular}{|l|c|c|c|c|c|c|}
\hline \multirow{2}{*}{ Fexofenadine } & \multicolumn{2}{|c|}{ Arithmetic mean } & \multicolumn{2}{c|}{ Geometric mean } & \multirow{2}{*}{$90 \%$ CI } & \multirow{2}{*}{ Acceptable range } \\
\cline { 2 - 5 } & Test & Reference & Test & Reference & & \\
\hline $\mathrm{C}_{\text {max }}(\mathrm{ng} / \mathrm{ml})$ & 625.0 & 629.5 & 544.0 & 550.9 & $83.72-116.49$ & $80-125$ \\
\hline $\mathrm{AUC}_{0-48}(\mathrm{ng} . \mathrm{hr} / \mathrm{ml})$ & 2965.0 & 3028.0 & 2673.0 & 2744.0 & $85.85-110.53$ & $80-125$ \\
\hline $\mathrm{AUC}_{0-\alpha}(\mathrm{ng} . \mathrm{hr} / \mathrm{ml})$ & 2954.0 & 3012.0 & 2666.0 & 2734.0 & $86.07-110.47$ & $80-125$ \\
\hline
\end{tabular}


have influenced the outcome of the study did not occur. There was no drop-out and all subjects who started the study continued to the end and were discharged in good health.

Both medications were readily absorbed from the gastrointestinal tract and fexofenadine was already measurable at the first sampling time $(0.5 \mathrm{hr})$ in all the volunteers. The plasma drug concentration-time curves show that the mean concentrations of fexofenadine were similar for the two formulations over the 48-hr sampling period (Fig. 1).

The results after statistical analysis of the main pharmacokinetic parameters are shown in Table 1. The parametric $90 \%$ confidence intervals for the main pharmacokinetic parameter values of $\mathrm{C}_{\max }, \mathrm{AUC}_{0-48}$ and $\mathrm{AUC}_{0-\alpha}$ lie entirely within the BE acceptance limits approved by EMEA and FDA (i.e. $80 \%$ to $125 \%$ ). The mean fexofenadine values were $\mathrm{T}_{\max } 1.84 \pm 0.87 \mathrm{hr} ; \mathrm{K}_{\mathrm{el}}$ $0.2368 \pm 0.02901 / \mathrm{hr} ; \mathrm{T}_{1 / 2} 2.97 \pm 0.32 \mathrm{hr}$ and $\mathrm{CL} 76.55 \pm$ $40.01 \mathrm{~L} / \mathrm{hr}$ for the test formulation, and $\mathrm{T}_{\max } 1.86 \pm 0.77 \mathrm{hr}$; $\mathrm{K}_{\mathrm{el}} 0.2382 \pm 0.0223 \mathrm{1} / \mathrm{hr} ; \mathrm{T}_{1 / 2} 2.94 \pm 0.29 \mathrm{hr}$ and CL 76.64 $\pm \mathrm{L} 42.7 \mathrm{1} / \mathrm{hr}$ for the reference formulation. Based on the nonparametric Wilcoxon test and the paired t-test, there were no significant differences (at $\mathrm{p}>0.05$ ) in $\mathrm{T}_{\max }, \mathrm{K}_{\mathrm{el}}$ $\mathrm{T}_{1 / 2}$, and $\mathrm{CL}$ values for either formulation.

\section{CONCLUSION}

The mean bioequivalence of $180 \mathrm{mg}$ fexofenadine tablets of the test formulation compared to the reference formulation was confirmed. Ninety \% CI of $\mathrm{AUC}_{0-48}$, $\mathrm{AUC}_{0-\alpha}$ and $\mathrm{C}_{\max }$ ratios of fexofenadine of these two prepa- rations fell within the $80-125 \%$ interval proposed by the US FDA ${ }^{7}$. Both formulations were equivalent in terms of rate and extent of absorption. Consequently, bioequivalence between the two formulations can be concluded.

\section{ACKNOWLEDGEMENTS}

We thank the Hospital and Policlinic Mèlník medical and paramedical staff for their valuable contribution.

\section{REFERENCES}

1. Golightly LK, Greos LS. Second-generation antihistamines: actions and efficacy in the management of allergic disorders. Drugs 2005; 65(3):341-84.

2. Morgan MM, Khan DA, Nathan RA. Treatment for allergic rhinitis and chronic idiopathic urticaria: focus on oral antihistamines. Ann Pharmacother 2005; 39(12):2056-64.

3. Bernstein DI, Schoenwetter WF, Nathan RA, Storms W, Mason J. Fexofenadine: a new nonsedating antihistamine is effective in the treatment of seasonal allergic rhinitis [abstract]. J Allergy Clin Immunol 1996; 97 (1 pt 3):435.

4. Molimard M, Diquet B, Benedetti MS. Comparison of pharmacokinetics and metabolism of desloratadine, fexofenadine, levocetirizine and mizolastine in humans. Fundam Clin Pharmcol 2004; 18(4):339-411.

5. Russell TL, Stoltz ML, Bhargava VO, Eller MG, Weir S. Acute and subchronic dose tolerance of fexofenadine HCL in healthy male subjects [abstract]. Ann Allergy Asthma Immunol 1996; 76(1):96.

6. Simons FER, Simons KJ. Pheripheral H1-blockade effect of fexofenadine. Ann Allergy Asthma Immunol 1997; 79:530-32.

7. FDA Guidelines, Bioequivalence Food and Drug Administration, Division of Bioequivalence, Office of Generic Drugs: Rockville, MD, 1 July 1992. 